\title{
Expert Statement: Pneumothorax Associated with One-Way Valve Therapy for Emphysema: 2020 Update
}

\author{
Marlies van Dijk ${ }^{a, b}$ Rick Sue ${ }^{c}$ Gerard J. Criner ${ }^{d}$ Daniela Gompelmann ${ }^{e}$ \\ Felix J.F. Herth ${ }^{f}$ D. Kyle Hogarth ${ }^{g}$ Karin Kloostera, Janwillem W.H. Kocks ${ }^{b}, h, i$ \\ Hugo G. de Oliveira ${ }^{j}$ Pallav L. Shah ${ }^{k, l, m}$ Arschang Valipour ${ }^{n}$ Dirk-Jan Slebos ${ }^{a, b}$ \\ aDepartment of Pulmonary Diseases, University Medical Center Groningen, University of Groningen, Groningen, \\ The Netherlands; ${ }^{b}$ GRIAC Research Institute, University of Groningen, University Medical Center Groningen, \\ Groningen, The Netherlands; ' ${ }^{A}$ dvanced Lung Institute, Banner University Phoenix, Phoenix, AZ, USA; ${ }^{\mathrm{d} D e p a r t m e n t}$ \\ of Thoracic Medicine and Surgery, Lewis Katz School of Medicine at Temple University, Philadelphia, PA, USA; \\ 'Department of Internal Medicine II, Division of Pulmonology, Medical University of Vienna, Vienna, Austria; \\ fDepartment of Pneumology and Critical Care Medicine, Thoraxklinik and Translational Lung Research Center \\ Heidelberg (TLRCH), University of Heidelberg, Heidelberg, Germany; ${ }^{9}$ Section of Pulmonary and Critical Care \\ Medicine, University of Chicago, Chicago, IL, USA; ${ }^{\text {h}}$ General practitioners Research Institute, Groningen, \\ The Netherlands; 'Observational and Pragmatic Research Institute, Singapore, Singapore; jServiço de Pneumologia \\ do Hospital de Clínicas de Porto Alegre, Universidade Federal do Rio Grande do Sul, Porto Alegre, Brazil; kRoyal \\ Brompton Hospital, London, UK; 'Chelsea \& Westminster Hospital, London, UK; m National Heart \& Lung Institute, \\ Imperial College, London, UK; ${ }^{n}$ Department of Respiratory and Critical Care Medicine, Karl-Landsteiner-Institute for \\ Lung Research and Pulmonary Oncology, Klinik Floridsdorf, Vienna Health Care Group, Vienna, Austria
}

\section{Keywords}

Bronchoscopy · Bronchoscopic lung volume reduction . Emphysema - One-way valves · Pneumothorax

\begin{abstract}
For selected patients with advanced emphysema, bronchoscopic lung volume reduction with one-way valves can lead to clinically relevant improvements of airflow obstruction, hyperinflation, exercise capacity, and quality of life. The most common complication of this procedure is pneumothorax with a prevalence of up to $\pm 34 \%$ of the treated patients. Patients who develop a pneumothorax also experience mean-
\end{abstract}

ingful clinical benefits once the pneumothorax is resolved. Timely resolution of a post-valve treatment pneumothorax requires skilled and adequate pneumothorax management. This expert panel statement is an updated recommendation of the 2014 statement developed to help guide pneumothorax management after valve placement. Additionally, mechanisms for pneumothorax development, risk assessment, prevention of pneumothorax, and outcomes after pneumothorax are addressed. This recommendation is based on a combination of the current scientific literature and expert opinion, which was obtained through a modified Delphi method.
C 2021 The Author(s)

Published by S. Karger AG, Basel karger@karger.com www.karger.com/res

Karger $\stackrel{\text { ' }}{5}$

BOPEN ACCESS
(C) 2021 The Author(s)

Published by S. Karger AG, Basel

This is an Open Access article licensed under the Creative Commons Attribution-NonCommercial-4.0 International License (CC BY-NC) (http://www.karger.com/Services/OpenAccessLicense), applicable to the online version of the article only. Usage and distribution for commercial purposes requires written permission.
Correspondence to:

Marlies van Dijk, m.van.dijk05@umcg.nl

Dirk-Jan Slebos, d.j.slebos@umcg.nl 


\section{Introduction}

For selected patients with advanced emphysema, bronchoscopic lung volume reduction (BLVR) with one-way valves can lead to clinically relevant improvements of airflow obstruction, hyperinflation, exercise capacity, and quality of life [1-3]. Since 2019, BLVR with valves is acknowledged in the COPD GOLD guidelines with evidence grade " $A$ " as a treatment option for patients with severe hyperinflation and severe emphysema and no collateral ventilation between the target lobe and ipsilateral lobe(s) [4]. The inclusion of BLVR treatment with valves in global treatment guidelines and increasing coverage by medical insurance in an increasing number of countries have resulted in a sharp increase in the number of BLVR valve procedures worldwide $[3,5]$. With an increasing number of procedures worldwide, there will also be an increase in the absolute number of adverse events related to BLVR procedures with valves. The most common complication associated with valve procedures is a pneumothorax, which occurs in $4.2-34.4 \%$ of treated patients $[6,7]$.

This consensus statement provides an updated recommendation of the in 2014 published expert statement on pneumothorax associated with endoscopic valve therapy for emphysema [8] developed by an expert panel to help guide pneumothorax management after valve placement. Additionally, mechanisms for pneumothorax development, risk assessment, prevention of pneumothorax, and outcomes after pneumothorax are discussed.

\section{Methods}

For this expert statement we reviewed the current scientific literature. However, for many of the topics discussed in his report there is no or inconclusive scientific evidence. To achieve expert consensus on these topics we performed a modified Delphi method [9], with a panel of 9 experts with extensive experience in BLVR with valves (median number of valve procedures performed was $>300$ [range minimum 70-maximum 1,000]). Themes of the questionnaires were: risk assessment, prevention, diagnosis, and treatment of pneumothorax after valve placement, and patient education. Two rounds were held given the prespecified criteria: $8 / 9 \mathrm{ex}-$ perts completed the first round, and $9 / 9$ of the invited experts completed the second round.

An extensive description of the modified Delphi procedure, the questionnaires and outcomes can be found in the online suppl. material; see www.karger.com/doi/10.1159/000516326 for all online suppl. material. Furthermore, for each statement on consensus between experts in this article there is a reference to the relevant question and round in the online suppl. material. For example, "Finally, there was consensus regarding homogeneous emphysema distribution and a fast development of atelectasis after valve placement as risk factors [Q1,R2]" ( $\mathrm{Q}=$ question, $\mathrm{R}=$ round).

\section{Brief Overview of Valve Procedure}

Patients with severe emphysema, severe static hyperinflation (residual volume $[\mathrm{RV}]>175 \%$ pred in heterogeneous emphysema, RV $>200 \%$ pred in homogenous emphysema) and no collateral ventilation between the target lobe and ipsilateral lobe(s) are eligible for valve treatment $[10,11]$. Contraindications are severe gas exchange impairment, severe airway pathology, frequent infectious exacerbations, and/or important cardiopulmonary comorbidity (e.g., suspicious pulmonary nodules, pulmonary fibrosis, and severe heart failure) $[3,10]$.

The preferred target lobe is the lobe with the most diseased lung tissue. In case of more than one potential target lobe, nuclear scanning can help identify the lobe with the least perfusion. The degree of heterogeneity should also be taken into consideration especially as treating a lobe where the ipsilateral lobe is better preserved has more favorable outcomes. Collateral ventilation can be assessed with quantitative CT analysis and/or measured during bronchoscopy with the Chartis ${ }^{\circledR}$ System (Chartis Pulmonary Assessment System, Pulmonx Corporation, Redwood City, CA, USA). The procedure for valve treatment is preferably performed under general anesthesia using flexible or rigid intubation. An alternative option is moderate to deep conscious sedation with spontaneous breathing. During bronchoscopy each airway of the target lobe should be totally occluded with one-way valves to prevent air flow into the treated lobe. Depending on the anatomy and airway sizes of the treatment lobe the valves are placed at the segmental and/or subsegmental level. Additional information on the optimal performance of valve treatment can be found in the best practice recommendations by Slebos et al. [10].

\section{Mechanisms of Pneumothorax after Valve Placement}

The atelectasis or volume loss that occurs in the target lobe following volume reduction allows the untreated ipsilateral lobe to expand to occupy the newly created space in the thoracic cavity. Brown et al. [12] showed that a part of the volume reduction in the target lobe is indeed redistributed to the ipsilateral lobe, with only a small portion redistributed to the contralateral lung. The expansion of the ipsilateral nontargeted lobe, which can be rapid and substantial, may in some cases exceed its limits of plasticity creating a bronchoalveolar fistula resulting in a pneumothorax. Rupture of blebs, bullae, and fragile lung tissue in the ipsilateral nontreated lobe are believed to be important contributing causes to a pneumothorax (Fig. 1) [13]. Another mechanism could be parenchymal rupture due to pre-existing pleural adhesion(s) as the lobe volumes shift (Fig. 2). A pneumothorax that results in a bronchoalveolar fistula has the potential to progress and precipitate clinical deterioration over a short amount of time if not treated by chest tube insertion. Another mechanism of pneumothorax is a pneumothorax ex vacuo [14]. In this condition, the lobar collapse results in an increase in the negative intrapleural pressure surrounding the collapsed lobe (Fig. 3). As a result, gas originating from the ambient tissues and blood are drawn into the pleural space surrounding the collapsed lobe while the seal between the visceral and parietal pleura of the adjacent lobe or lobes remains intact [15]. No bronchoalveolar fistula is present in these cases, and the pleural air is expected to resolve spontaneously over time without the need for chest tube insertion. Typically, these patients have little to no symptoms, or already experience the induced lung volume reduction benefit. An interlobar pneumothorax is an uncommon occurrence after valve treatment, and can be difficult to diagnose on 

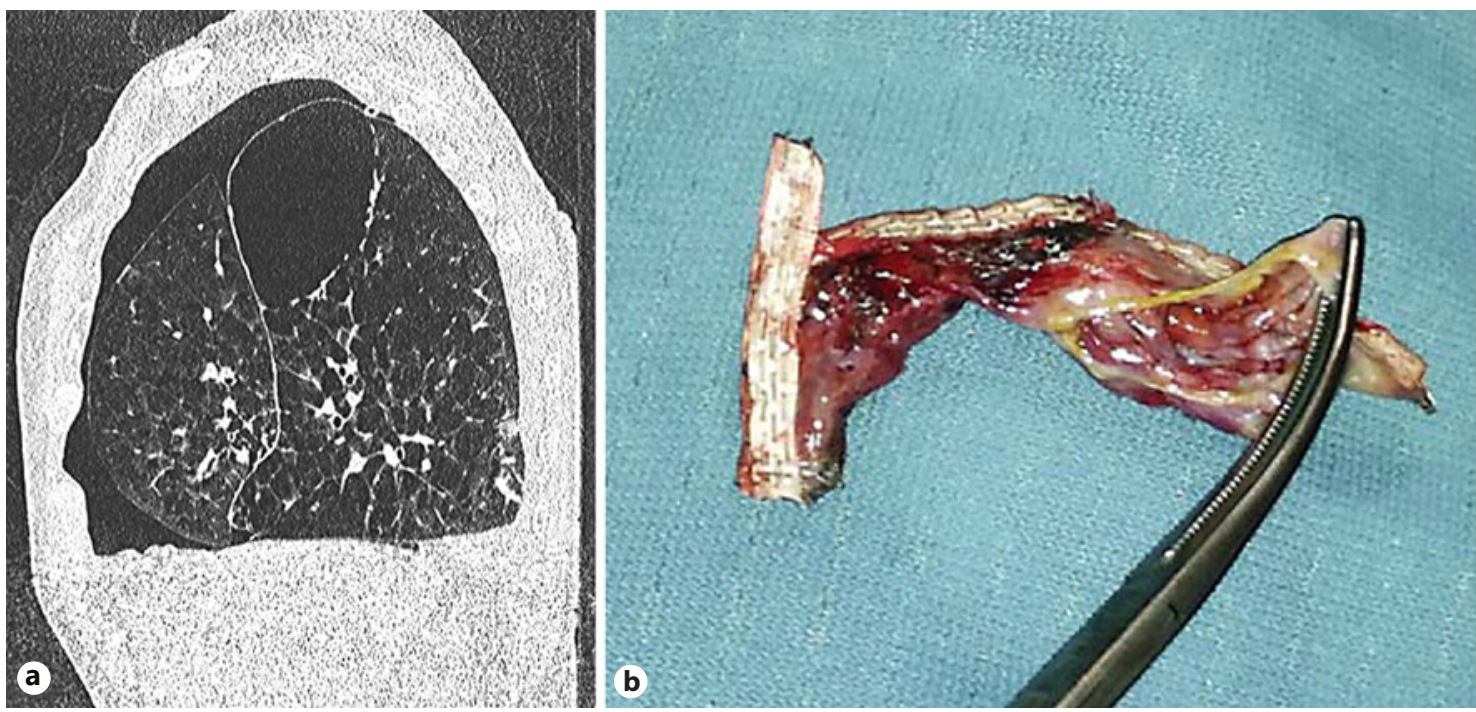

Fig. 1. a Pneumothorax and large bulla in the right lower lobe after valve treatment of the right upper lobe. b Example of VATS-resected lung tissue with ruptured bullae after valve treatment that caused a persistent sig-

chest X-ray [8]. Finally, a pneumothorax might theoretically also originate from the barotrauma response to the acute volume reduction in the treated lobe. In this instance, the absence of an air leak might be due to the valves closing the originating bronchi. These cases of pneumothorax are expected to be less extensive on $\mathrm{X}$-ray, and patients report minimal or no complaints. A "wait-andsee" policy is potentially successful in these patients.

\section{Prevalence and Outcome of Pneumothorax after Valve}

\section{Treatment}

The prevalence of pneumothorax in randomized controlled trials (RCTs) investigating treatment with valves was $4.2-34.4 \%$ in the treatment groups compared to $0-4 \%$ in the control groups (Table 1) $[6,16-23]$. For RCTs investigating endobronchial valves (Zephyr ${ }^{\circledR}$ EBV, Pulmonx Corporation, Redwood City, CA, USA) there was a clear increase in the prevalence of pneumothorax in more recent trials [19-21] compared to earlier trials [16-18]: 17.6$34.4 \%$ versus $4.2-8 \%$. The most likely explanation for this is a better patient selection in the more recent trials where patients were only treated with endobronchial valves in the absence of collateral ventilation, which was measured during bronchoscopy with the Chartis System. The use of Chartis for optimal patient selection has led to a greater target lobe volume reduction, greater treatment effect, and subsequently more pneumothoraces (Table 1). Similarly, the relationship between atelectasis and postinterventional pneumothorax was demonstrated in a case series of patients with emphysema using the Spiration valve system (formally intrabronchial valve) (SVS, Spiration Inc./Olympus Respiratory America, Redmond, WA, USA) [24]. In this trial, where patient selection was based on QCT (to determine absence of collateral ventilation) and not all patients received a full lobar occlusion with valves, the overall incidence of pneumothorax during a 12-month period was $12.1 \%$. However, analysis of those patients who underwent a complete lobar exclusion (only of the left upper lobe) revealed a pneumothorax rate of $29 \%$ [24]. In the more recent EMPROVE trial

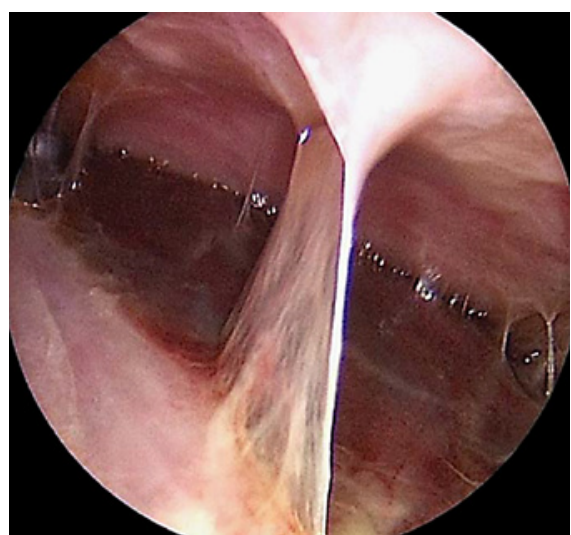

Fig. 2. Pleural adhesions as observed during VATS. VATS, videoassisted thoracoscopy.

with the SVS, quantitative CT analysis was used to assess the risk of collateral ventilation [23]. In this study, the pneumothorax rate was $25.7 \%$ in 113 treated subjects, similar to pneumothorax rates in the trials using Chartis and EBVs.

The majority of pneumothoraces (up to $86 \%$ ) occur within the first 3 days after treatment $[6,23,25,26]$. In general, the outcome of pneumothorax after valve treatment is resolution of the pneumothorax and there are no long-term sequelae. However, prolonged air leak is common. For example, in one retrospective trial the air leak persisted for over a week in $68 \%$ of pneumothoraces [27]. Of 799 patients who were treated in 9 RCTs, a fatal pneumothorax occurred in 6 patients $(0.75 \%)$, and represents $4.6 \%$ of all patients with a pneumothorax $[6,16-23]$. Post hoc analysis of the pneumothorax events in the LIBERATE Study revealed that if the 

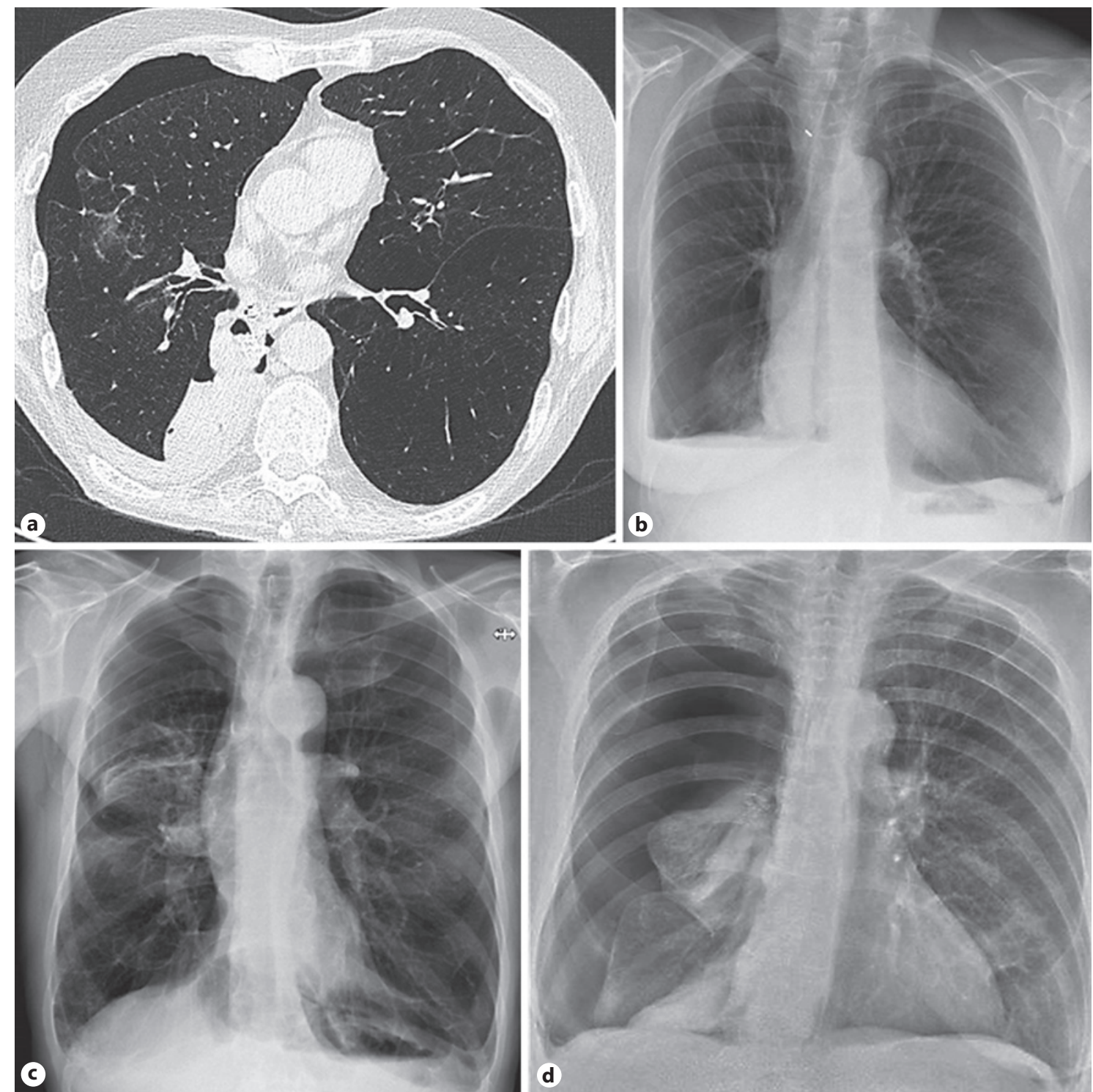

Fig. 3. a Pneumothorax ex vacuo on a chest CT scan after valve treatment in the left upper lobe. The patient received no intervention. The pneumothorax was asymptomatic and resolved within 4 weeks. b, $\mathbf{c}$ Pneumothorax ex vacuo on chest X-ray. d Complete pneumothorax for which acute intervention is needed.

treated lobe was not the most diseased lobe (i.e., the second best target was chosen) and the emphysema destruction in the contralateral lung was $>60 \%$ (measured at -910 Hounsfield Units), the patient would be at a higher risk of death or require removal of all valves [6]. Of note, of the 6 fatal pneumothoraces mentioned above, 4 were in patients who were not treated in the most diseased lung lobe and had emphysema destruction of $>60 \%$ in the contralateral lung, one pneumothorax occurred in the contralateral lung and one tension pneumothorax occurred during the removal of valves.

"Real life" unpublished data from the University Medical Center in Groningen (BREATHE-NL Registry, NCT02815683) shows similar outcomes compared to the scientific literature. Of the patients treated between September 2016 and March 2020, the overall pneumothorax rate after valve treatment was $16 \%$, with the number of patients requiring a chest tube being $12 \%$ of treated patients.

A post hoc analysis of 3 prospective studies analyzing outcomes for patients who developed a pneumothorax after valve treatment demonstrated substantial reductions in the target lobar volume (65 $\pm 36 \%)$ at follow-up [27]. This is of particular clinical importance as patients with a $>50 \%$ reduction in target lobar volume demonstrate clinically significant benefits in hyperinflation, exercise capacity, quality of life, and airflow obstruction [28]. A retrospective analysis of 70 patients with pneumothorax confirmed that a pneumothorax generally has no negative impact on the clinical status [29]. Furthermore, in another large retrospective analysis investigating longterm effects of valve treatment, the occurrence of a pneumothorax 
Table 1. Prevalence, treatment, and outcome of pneumothorax after BLVR with one-way valves

\begin{tabular}{|c|c|c|c|c|c|c|c|c|c|c|}
\hline \multirow[t]{2}{*}{ Trial } & \multirow{2}{*}{$\begin{array}{l}\text { Type of } \\
\text { one-way } \\
\text { valve }\end{array}$} & \multirow{2}{*}{$\begin{array}{l}\text { Follow-up, } \\
\text { months }\end{array}$} & \multirow{2}{*}{$\begin{array}{l}\text { Treated } \\
\text { patients, } n\end{array}$} & \multicolumn{5}{|c|}{ Pneumothorax } & \multirow{2}{*}{$\begin{array}{l}\text { Average TLVR, } \\
\mathrm{mL}\end{array}$} & \multirow{2}{*}{$\begin{array}{l}\text { Complete } \\
\text { atelectasis, } \\
n(\%)\end{array}$} \\
\hline & & & & $\begin{array}{l}\text { Ptx, } \\
n\end{array}$ & $\begin{array}{l}\text { patients with } \\
\text { Ptx, } n(\%)\end{array}$ & $\begin{array}{l}\text { chest } \\
\text { tube, } n\end{array}$ & $\begin{array}{l}\text { valve } \\
\text { removal, } n\end{array}$ & $\begin{array}{l}\text { death from } \\
\text { Ptx, } n(\%)\end{array}$ & & \\
\hline Sciurba et al. [16] & Zephyr & 3 & 214 & 9 & $9(4.2)$ & 6 & Unknown & $0(0)$ & 378.4 & Unknown \\
\hline Herth et al. [17] & Zephyr & 3 & 111 & 5 & $5(4.5)$ & 5 & Unknown & $0(0)$ & Unknown & $20(18)$ \\
\hline Valipour et al. [20] & Zephyr & 3 & 43 & 12 & $11(25.5)$ & 12 & 5 & $0(0)$ & $1,195 \pm 683$ & Unknown \\
\hline Kemp et al. [21] & Zephyr & 6 & 65 & 20 & $19(29.2)$ & 11 & 5 & $1(1.5)^{\$}$ & $1,090 \pm 620$ & Unknown \\
\hline Criner et al. [6] & Zephyr & 12 & 128 & 46 & $44(34.4)$ & 38 & 12 & $3(2.3)$ & $1,030 \pm 680$ & Unknown \\
\hline Li et al. [22] & SVS & 6 & 66 & 5 & $5(7.6)$ & 5 & 0 & $0(0)$ & 757 & Unknown \\
\hline Criner et al. [23] & SVS & 6 & 113 & 32 & $29(25.6)$ & 12.4 & 11 & $1(0.9) *$ & $974 \pm 736$ & Unknown \\
\hline
\end{tabular}

Zephyr, Zephyr endobronchial valve; SVS, Spiration valve system; Ptx, pneumothorax; TLVR, target lung volume reduction; BLVR, bronchoscopic lung volume reduction. * Patient developed cough, and a decision was taken to remove the valves 49 days after they had been placed. At the time of removal, which was difficult, the patient developed a tension pneumothorax with an ongoing significant air leak, in-hospital cardiac arrest. ${ }^{*}$ Pneumothorax in the contralateral lung. ${ }^{\$}$ Cardiac arrest during hospitalization for a pneumothorax.

Table 2. Possible risk factors for developing a pneumothorax after valve treatment and possible risk factors for a poor outcome of pneumothorax after valve treatment

Possible risk factors for a pneumothorax after valve treatment

Possible risk factors for a poor outcome in case of pneumothorax after valve treatment

- Significant pleural adhesions in target lung

- Significant paraseptal emphysema

- Large difference in volume of the target lobe versus ipsilateral lobe(s)

- Target lobe not the most destructed lobe

- High emphysematous destruction score of ipsilateral nontreated lobes(s)

- High destruction score in the ipsilateral lobe(s) and contralateral lung

- Pneumothorax in the best perfused lung

- Homogeneous emphysema distribution

- Very severe airflow obstruction $\left(\mathrm{FEV}_{1}<15 \%\right)$

- Severely impaired diffusing capacity $\left(\mathrm{DL}_{\mathrm{CO}}<20 \%\right)$

- Rapid onset of atelectasis

- Severe chronic respiratory failure $\left(\mathrm{PaCO}_{2}>55 \mathrm{~mm} \mathrm{Hg}, \mathrm{PaO}_{2}<45 \mathrm{~mm} \mathrm{Hg}\right)$

did not influence survival [30]. More recently, the LIBERATE trial demonstrated no differences in outcome for patients who did and did not develop a pneumothorax after valve treatment [6].

\section{Predicting Pneumothorax: Risk Assessment}

Since pneumothorax is a common adverse event following valve treatment, alertness for the occurrence of a pneumothorax after procedure should always be high. However, there are certain risk factors that are considered to increase the chance of a pneumothorax or a poor outcome of pneumothorax after procedure (i.e., prolonged air leak or death; Table 2).

\section{Pleural Adhesions}

Pleural adhesions can be identified on a Chest CT scan as fibrotic bands with pleural involvement [31]. With respect to the presence of pleural adhesions and risk of pneumothorax, there is ambiguity in the literature. One retrospective study demonstrated an increased risk of pneumothorax in patients with a higher number or greater size of pleural adhesions [31], but in another retrospective study the presence of pleural adhesions was associated with a lower risk of pneumothorax [26]. In the large multicenter
LIBERATE trial investigating Zephyr valves, the presence of pleural adhesions was not identified as a risk factor for pneumothorax [6]. Nevertheless, the expert panel does regard the presence of pleural adhesions (both number and size) as an important risk factor for pneumothorax after valve treatment, where adhesions in the untreated lobe are more likely to be contributing to the risk of developing a pneumothorax [Q1,R1].

\section{Emphysema Phenotype}

The presence of paraseptal emphysema was identified as a risk factor for the development of a pneumothorax by the expert panel [Q1,R1]. The presence of blebs or paraseptal cysts did not have a significant predictive value for a pneumothorax in either the prospective LIBERATE trial or the retrospective analysis of Gompelmann et al. [6, 26]. Compared to centrilobular emphysema, panlobular emphysema was found to be protective in the study by Gompelmann et al. [26].

\section{Lobar Volumes and Emphysema Destruction}

Gompelmann et al. [26] further identified a large difference in the volume of the target lobe versus the ipsilateral lobe(s), a high 
destruction score in the ipsilateral untreated lobe and a high baseline $\mathrm{RV}$ as factors increasing the risk of pneumothorax related to valve treatment. The volume difference between target and ipsilateral lobe(s) was also identified as a factor increasing the risk of pneumothorax by the expert panel [Q1,R1]. Finally, there was consensus regarding homogeneous emphysema distribution and a fast development of atelectasis after valve placement as risk factors [Q1,R2].

It has been hypothesized that the risk of pneumothorax following valve treatment is higher for an upper lobe treatment compared to treatment in a lower lobe. Two trials did demonstrate a nonsignificant trend toward more pneumothoraces when treating upper lobes as opposed to lower lobes [19, 32]. There was no consensus within the expert panel with respect to this risk factor [Q4,R1].

As mentioned above, post hoc analysis of data from the LIBERATE trial revealed that patients not treated in the most diseased lobe (treated in secondary lobe in contralateral side) and in whom the emphysema destruction score was $>60 \%$ at -910 Hounsfield Units on chest CT, were at a higher risk of a complex pneumothorax (defined as leading to death or requiring valve removal) if one were to occur. The 3 patient deaths attributed to a pneumothorax event in this trial were later identified to be in this higher risk group [6].

In the large multicenter NETT, lung volume reduction surgery was demonstrated to have a positive effect on lung function, exercise tolerance, and quality of life. However, during the trial a highrisk patient category was identified who had a significantly higher 90-day mortality (28.6 vs. $5.2 \%$ ). These were patients with an $\mathrm{FEV}_{1}$ of below $20 \%$ of predicted and either a homogeneous emphysema distribution or diffusing capacity $\left(\mathrm{DL}_{\mathrm{CO}}\right)$ below $20 \%$ of predicted [33]. Two retrospective trials investigated valve treatment in patients with an $\mathrm{FEV}_{1}<20 \%$ and $\mathrm{DL}_{\mathrm{co}}<20 \%$, respectively, and demonstrated no increased risk for pneumothorax or increased mortality $[34,35]$. However, these were both small trials and there was consensus between the expert panel that both a very severe airflow obstruction and severely impaired diffusing capacity at baseline increase the risk of a poor outcome (i.e., death or prolonged air leak) in case of pneumothorax postvalve treatment [Q2,R1]. Other factors identified by the expert panel that increase the risk of an unfavorable outcome in case of pneumothorax were high emphysema destruction scores in the ipsilateral nontarget lobe and contralateral lung, the development of a pneumothorax in the best perfused lung, and severely impaired gas exchange at baseline [Q2,R1; Q2,R2].

\section{Preventing and Diagnosing Pneumothorax during and after Procedure}

Experts have no consensus about strategies during valve procedure in order to reduce pneumothorax risk [Q3,R1]. Some suggestions are adjusting ventilator settings (low frequency ventilation, long expiration time), avoid tracheal intubation, administration of cough suppressants (opioids, lidocaine, codeine), reducing procedure time, avoidance of suctioning after placement of the last valve and $24-$ to $72-\mathrm{h}$ relative rest after procedure.

In a prospective analysis of patients treated with a new size Zephyr valve, Klooster et al. [36] found a very low pneumothorax rate $(3 \%)$ despite a significant clinically relevant reduction in lung volume. The authors suggested that extubation of patients while they are deeply sedated with strong cough suppression for the first hour after treatment (intravenous lidocaine and opioids) and little to no mobilization until the morning after the procedure could be possible explanations for the low pneumothorax rate.
Staged placement of valves in the target lobe during 2 sequential bronchoscopy procedures has been reported to reduce pneumothorax rate while providing clinically relevant lung volume reduction effect. Two single center uncontrolled case series reported a pneumothorax rate of 4.5 and $5.2 \%$ with sequential valve placement $[37,38]$. However, a staged placement of valves was not recommended by the expert panel [Q4,R1]. One argument for this could be that an additional bronchoscopy also increases risk of bronchoscopy-related complications [39]. Although the results from the case studies may appear encouraging, given the impact of changing the treatment strategy from 1 to 2 procedures, a solid RCT should be performed to give a conclusive answer.

Since the majority of pneumothoraces occurs in the first 3 days after valve treatment a hospital admission of at least 3 nights after the procedure is advised by the expert panel [Q6,R1]. Observation during hospitalization should include clinical examination, assessment of vital signs at least once daily, and instructing the patient to immediately refer any chest pain or increase in dyspnea [Q8,R1; Q5,R2]. It is further recommended that multiple chest X-rays be taken during the hospital admission, with the first X-ray taken within a few hours after the procedure $[Q 9, R 1]$. In case of persisting (severe) chest pain, increased dyspnea, lower oxygen saturations, or the presence of a pneumothorax ex vacuo the expert panel advises prolonging the hospital admission [Q7,R1]. One retrospective analysis found significantly less pneumothoraces in 40 patients who were prescribed bed rest, and "as needed" codeine for the first 2 days after valve treatment compared to 32 patients with no restrictions on mobilization and no codeine $(25$ vs. $5 \%, p=$ 0.02 ); there were no differences in clinical outcomes between the groups [40]. However, in this retrospective trial, the number of patients was limited, and hence, the expert panel has not recommended any restriction on mobilization during hospital admission [Q10,R1]. One important concern for prescribing restrictive mobilization during hospital admission may be the occurrence of a delayed pneumothorax posthospital admission.

Patient and caregiver education before hospital discharge is important and should include information about symptoms of an acute pneumothorax (acute dyspnea and/or chest pain), need to seek immediate emergency care, the emergency number and what information to provide to medical personnel, what activities to avoid and for how long [Q14,R1]. However, there was no consensus between experts regarding the exact advice for patients with respect to household chores, physiotherapy, and air travel during the first weeks after treatment [Q11-13,R1]. This is probably in part because of differences in healthcare systems and whether travel between hospital and home involves transportation by air.

\section{Pneumothorax Management}

Patients who are candidates for endoscopic valve therapy have severe emphysema with hyperinflation, impaired gas exchange, and exercise capacity. Thus, these patients are less likely to tolerate a pneumothorax than patients with a primary spontaneous pneumothorax. Skilled and adequate pneumothorax management is therefore essential in this patient population and every pneumothorax, in particular a tension pneumothorax, can be life threatening [24]. It is therefore recommended by the expert panel that all medical staff involved in the postprocedure care of these patients in an institution where valve treatments are performed are thoroughly educated in diagnosing a pneumothorax and pneumothorax management [Q16,R1; Q6,R2]. An emergency kit for treating 
Table 3. Recommendations for optimal postvalve treatment care in the ward based on consensus

Hospital admission for at least 3 nights

Prolong in case of (severe) chest pain, increased dyspnea, lower oxygen saturations, or the presence of a pneumothorax ex vacuo

High awareness of risk of pneumothorax

Training and education of medical staff

Clear information on procedure in medical charts

Multiple chest X-rays during admission

Emergency pneumothorax kit available on the ward*

Patient and caregiver education before discharge

Patient warning card

*Recommended contents of pneumothorax emergency kit

A chest tube (minimal size 10-14 French) and drainage system

A needle for immediate needle decompression

Materials for disinfecting the skin

Materials for local anesthesia

Surgical drapes

Sterile gloves, a sterile gown/scrubs, scrub caps, surgical mask

Materials for securing the chest drain (suture set, bandages, and tape)

Pigtail catheter

pneumothoraces should be close at hand, at a minimum in the ward, but wherever possible, by the patient's bedside [Q15,R1]. The recommended contents of the emergency kit can be found in Table 3. The updated management recommendation (Fig. 4), based on the consensus procedure by the expert panel, is intended to provide guidance for physicians dealing with these cases in clinical practice. By following these recommendations, traumatic scenarios, prolonged drainage, extended hospital stays, and/or surgery might be minimized in many cases.

Based on clinical signs and symptoms, the pneumothorax is classified as symptomatic or asymptomatic. If the pneumothorax is asymptomatic, clinical observation may be enough and a repeat $\mathrm{X}$-ray is recommended. Patients with an asymptomatic pneumothorax can be discharged if the pneumothorax is stable or improving on the chest X-ray and they are clinically stable $[Q 4, R 2]$. If clinical symptoms deteriorate or the size of the pneumothorax is enlarging, immediate insertion of a chest drain is required.

For every symptomatic pneumothorax insertion of a chest drain is required [Q17,R1]. The minimal advised chest drain size is 10-14 French [Q20,R1]. If available, an electronic drain system is preferable to a water seal system, provided the air leak is not too high for the electronic drainage system [Q21,R1]. Suction is generally not advised to start with but is an option in case of a clinically unstable patient, severe subcutaneous ("surgical”) emphysema or if the lung does not expand after one or more days of chest drainage $[Q 19, R 1]$. The chest drain can be removed when there has been no air leak for over $24 \mathrm{~h}$ and the pneumothorax is stable or improving on chest X-ray [Q11,R2]. Switching to a larger chest drain or placement of an additional chest tube should be considered in the following situations: If the patient is deteriorating, subcutaneous emphysema is increasing or there is a very high flow and the lung does not expand despite a functioning chest drain [Q22,R1]. Removal of one or 2 valves can be considered in case of a persistent high air leak (i.e., $>3$ days) or if the patient clinically deteriorates [Q23,R1]. This is likely to return the target lobe to its (hyperinflated) pretreatment state and may promote pneumothorax heal-

Pneumothorax Associated with One-Way

Valve Therapy for Emphysema ing by reestablishing pleural contact. The lack of full expansion and pleural sealing of the untreated lobe might however also be due to endobronchial mucus plugging requiring bronchoscopic suction. Replacement of valves can be considered after valve removal to manage a pneumothorax, but not within the first 5 weeks after the pneumothorax has resolved [Q25,R1]. There is no published data on recurrence of pneumothorax after valve replacement. However, in 2 expert centers, the recurrence rate was 17 and 29\%, respectively.

In cases with a persistent air leak, performing a CT scan can also be considered to guide treatment options and/or rule out aberrant chest tube placement [Q12,R2]. Additional treatment options for a prolonged air leak are surgery, use of a Heimlich valve or mechanical or chemical pleurodesis [Q27,R1]. The timing and choice of the therapeutic approach may largely depend on the patient's condition, patient preference, and the experience with and availability of these treatment options at the institution where the valve treatment was performed. In patients with severe heterogeneous emphysema, the surgical approach might be conducted with the intent of volume reduction, though high rates of cardiopulmonary morbidity, and mortality need to be taken into consideration [41]. Most patients with a valve-associated pneumothorax however do not require surgical interventions and can be safely treated with a chest tube in the presence of a prolonged air leak. Discharge with a Heimlich valve can be considered, provided the patient is clinically stable, hospital care is nearby $(<30 \mathrm{~min})$ in case of drain dysfunction and the patient has been educated about drain care [Q8,R2; Q9,R2].

\section{Limitations}

This consensus statement has limitations. The scientific literature related to pneumothorax occurrence after valve treatment largely consists of post hoc and retrospective analyses. This introduces an important selection bias and may also explain at least some of the discrepancies between the literature and expert opinion. For example, patients with large bullae on the chest CT are 


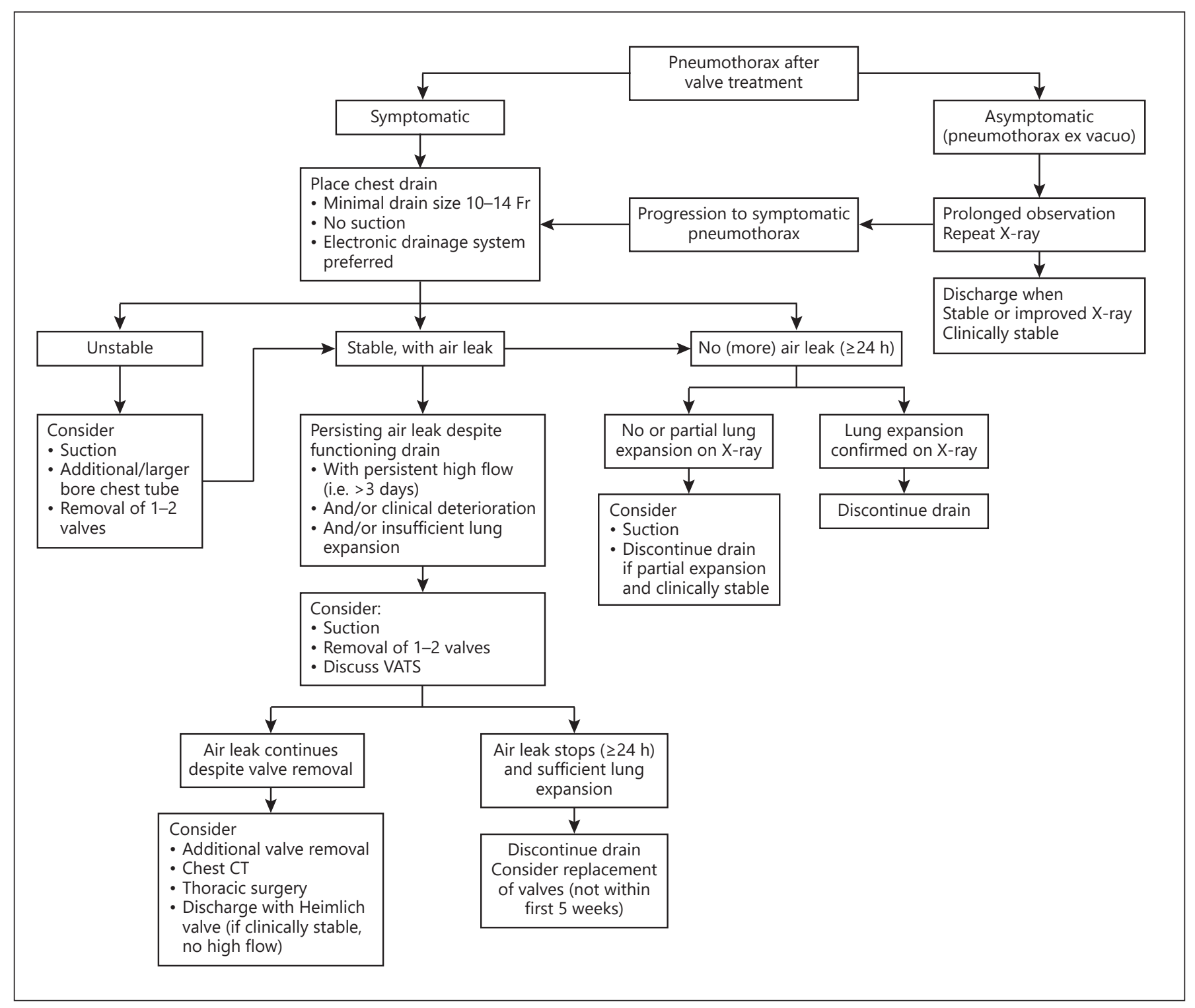

Fig. 4. Pneumothorax management recommendations. The recommended timelines in the proposed algorithm may differ individually depending on the patient's clinical status, the air leak volume, patient preference, and/or the local resources and expertise. VATS, video-assisted thoracic surgery.

commonly excluded from participating in trials investigating valve treatment. Thus, the fact that clinical trials did not find an elevated pneumothorax risk in patients with paraseptal bullae or blebs could be influenced by selection bias. Furthermore, the recommendations presented here are largely derived from clinical experience and a consensus of expert opinions, rather than scientific evidence or intervention studies. However, by introducing a modified Delphi method, we have aimed to take a more systemic approach to establish the expert opinion. Nevertheless, there is still a need for further prospective research into both baseline predictors of a pneumothorax and management strategies of pneumothorax. This may help optimize the risk-to-benefit ratio of patients undergoing valve therapy for lung volume reduction.

\section{Conclusion}

The occurrence of a pneumothorax and its management should be considered routine clinical care when performing BLVR with valves in patients who have progressive disease, severely compromised lung tissue, and limited therapeutic options. With this in mind, the authors would like to propose a pragmatic management plan that attempts to guide physicians in daily practice. Given optimized patient selection, the risk-to-benefit ratio of a pneumothorax appears to be acceptable as many 
Table 4. Future research questions regarding pneumothorax as a complication of valve treatment

Is there an increased pneumothorax risk, when?

There is fast development of an atelectasis after valve treatment?

The Chartis measurement is CV-negative in a short amount of time?

There is moderate paraseptal emphysema?

Can the risk of pneumothorax be lowered by?

Performing a staged valve placement? Investigated in a randomized controlled trial

Prescribing bed rest for one or more days after valve treatment?

Administering cough suppressants during or after procedure?

Does the use of point-of-care chest ultrasound have additional value in a timely diagnosis of pneumothorax after valve treatment?

Is there a place for prophylactic chest tube placement? For example, when there is a great imbalance between the treatment lobe and ipsilateral lobe(s)

of these patients develop substantial improvements in functional outcomes after resolution of the pneumothorax.

\section{Future Research Questions}

Future research questions regarding pneumothorax as a complication of valve treatment can be found in Table 4 .

\section{Funding Sources and Conflict of Interest Statement}

M.D. has no financial disclosures or conflicts of interest. R.S. has received travel and lecture fees from PulmonX. G.J.C. reports grants, personal fees, and nonfinancial support from Galaxo Smith Kline; grants, personal fees, and other from Boehringer Ingelheim; grants and personal fees from Chiesi; grants and personal fees from Mereo; personal fees from Verona; grants, personal fees, and nonfinancial support from Astra Zeneca; grants, personal fees, nonfinancial support, and other from Pulmonx; grants and personal fees from Pneumrx; personal fees from BTG; grants, personal fees, nonfinancial support, and other from Olympus; grants and personal fees from Broncus; personal fees from EOLO; personal fees from NGM; grants and personal fees from Lungpacer; grants from Alung; grants and personal fees from Nuvaira; grants and personal fees from ResMed; grants and personal fees from Respironics; grants from Fisher Paykel; grants and personal fees from Patara; grants from Galapgos; personal fees from Amgen; personal fees from Medtronic Vascular; personal fees and nonfinancial support from Spiration; personal fees from Auris Health; personal fees from CSA Medical; personal fees from Novartis Pharma AG; nonfinancial support from Intuitive Surgical, Inc; personal fees from Regeneron Healthcare Solutions, Inc; and other from Philips Electronics North American
Corp, outside the submitted work. D.G. has received travel and lecture fees from Olympus and PulmonX. F.H. has received consultancy and lecture fees from Olympus and PulmonX. D.K.H. has received consultancy fees from Olympus and PulmonX and is a consultant for Eolo. K.K. has received travel and lecture fees from PulmonX. J.W.H.K. has no financial disclosures or conflicts of interest relating to the current paper. H.G.O. has no financial disclosures or conflicts of interest. P.L.S. has received consultancy and lecture fees from Olympus and PulmonX. A.V. has received speaker fees from Olympus and PulmonX. D.S. is an investigator and advisor to PulmonX.

\section{Author Contributions}

M.D. contributed to the development of the questionnaires, analysis of the outcomes, and the writing of the manuscript. R.S. contributed to the development of the questionnaires, was part of the expert panel, and contributed to the revision of the manuscript. G.J.C., D.G., F.J.F., D.K.H., H.G.O., P.L.S., and A.V. were part of the expert panel and contributed to the revisions of the manuscript. K.K. contributed to the writing of the manuscript. J.W.H.K. has expertise on the use of the Delphi method and contributed to the development of the modified Delphi method used for the current study. D.J.S. contributed to the development of the questionnaires and analysis of the outcomes, was part of the expert panel, and contributed to the writing of the manuscript.

\section{References}

1 Majid A, Labarca G, Uribe JP, Kheir F, Pacheco C, Folch E, et al. Efficacy of the spiration valve system in patients with severe heterogeneous emphysema: a systematic review and meta-analysis. Respiration. 2020;99(1): 62-72.

2 van Geffen WH, Slebos DJ, Herth FJ, Kemp SV, Weder W, Shah PL. Surgical and endoscopic interventions that reduce lung volume for emphysema: a systemic review and meta-analysis. Lancet Respir Med. 2019;7(4):313-24. 
3 Hartman JE, Vanfleteren L, van Rikxoort EM, Klooster K, Slebos DJ. Endobronchial valves for severe emphysema. Eur Respir Rev. 2019; 28(152): 180121.

4 Singh D, Agusti A, Anzueto A, Barnes PJ, Bourbeau J, Celli BR, et al. Global strategy for the diagnosis, management, and prevention of chronic obstructive lung disease: the GOLD science committee report 2019. Eur Respir J. 2019;53(5):1900164.

5 Hartman JE, Klooster K, Slebos DJ. From bench to bedside: implementation of endobronchial valve treatment for patients with advanced emphysema in routine clinical care. Respiration. 2020;99(2):187-8.

6 Criner GJ, Sue R, Wright S, Dransfield M, Rivas-Perez $\mathrm{H}$, Wiese T, et al. A multicenter randomized controlled trial of zephyr endobronchial valve treatment in heterogeneous emphysema (LIBERATE). Am J Respir Crit Care Med. 2018;198(9):1151-64.

7 Koster TD, Klooster K, Ten Hacken NHT, van Dijk M, Slebos DJ. Endobronchial valve therapy for severe emphysema: an overview of valve-related complications and its management. Expert Rev Respir Med. 2020;14: 1235-47.

8 Valipour A, Slebos DJ, de Oliveira HG, Eberhardt R, Freitag L, Criner GJ, et al. Expert statement: pneumothorax associated with endoscopic valve therapy for emphysema: potential mechanisms, treatment algorithm, and case examples. Respiration. 2014;87(6):513-21.

9 Turoff M, Linstone HA. The delphi method: techniques and applications. Addison-Wesley Publishing Company; 1975.

10 Slebos DJ, Shah PL, Herth FJ, Valipour A. Endobronchial valves for endoscopic lung volume reduction: best practice recommendations from expert panel on endoscopic lung volume reduction. Respiration. 2017;93(2):138-50.

11 Herth FJF, Slebos DJ, Criner GJ, Valipour A, Sciurba F, Shah PL. Endoscopic lung volume reduction: an expert panel recommendation Update 2019. Respiration. 2019;97(6):548-57.

12 Brown MS, Kim HJ, Abtin FG, Strange C, Galperin-Aizenberg M, Pais R, et al. Emphysema lung lobe volume reduction: effects on the ipsilateral and contralateral lobes. Eur Radiol. 2012;22(7):1547-55.

13 Shen KR, Cerfolio RJ. Decision making in the management of secondary spontaneous pneumothorax in patients with severe emphysema. Thorac Surg Clin. 2009;19(2):233-8.

14 de Oliveira HG, Macedo-Neto AV, John AB, Jungblut S, Prolla JC, Menna-Barreto SS, et al. Transbronchoscopic pulmonary emphysema treatment: 1-month to 24-month endoscopic follow-up. Chest. 2006;130(1):190-9.

15 Woodring JH, Baker MD, Stark P. Pneumothorax ex vacuo. Chest. 1996;110(4):1102-5.

16 Sciurba FC, Ernst A, Herth FJ, Strange C, Criner $\mathrm{GJ}$, Marquette $\mathrm{CH}$, et al. A randomized study of endobronchial valves for advanced emphysema. N Engl J Med. 2010;363(13):1233-44.

17 Herth FJ, Noppen M, Valipour A, Leroy S, Vergnon JM, Ficker JH, et al. Efficacy predic- tors of lung volume reduction with Zephyr valves in a European cohort. Eur Respir J. 2012;39(6):1334-42.

18 Davey C, Zoumot Z, Jordan S, McNulty WH, Carr DH, Hind MD, et al. Bronchoscopic lung volume reduction with endobronchial valves for patients with heterogeneous emphysema and intact interlobar fissures (the BeLieVeRHIFi study): a randomised controlled trial. Lancet. 2015;386(9998):1066-73.

19 Klooster K, ten Hacken NH, Hartman JE, Kerstjens HA, van Rikxoort EM, Slebos DJ. Endobronchial valves for emphysema without interlobar collateral ventilation. N Engl J Med. 2015;373(24):2325-35.

20 Valipour A, Slebos DJ, Herth F, Darwiche K, Wagner M, Ficker JH, et al. Endobronchial valve therapy in patients with homogeneous emphysema. results from the IMPACT study. Am J Respir Crit Care Med. 2016;194(9): 1073-82.

21 Kemp SV, Slebos DJ, Kirk A, Kornaszewska $\mathrm{M}$, Carron K, Ek L, et al. A multicenter randomized controlled trial of zephyr endobronchial valve treatment in heterogeneous emphysema (TRANSFORM). Am J Respir Crit Care Med. 2017;196(12):1535-43.

22 Li S, Wang G, Wang C, Gao X, Jin F, Yang H, et al. The REACH Trial: a randomized controlled trial assessing the safety and effectiveness of the spiration $(\mathrm{R})$ valve system in the treatment of severe emphysema. Respiration. 2019;97(5):416-27.

23 Criner GJ, Delage A, Voelker K, Hogarth DK, Majid A, Zgoda M, et al. Improving lung function in severe heterogenous emphysema with the spiration valve system (EMPROVE). A multicenter, open-label randomized controlled clinical trial. Am J Respir Crit Care Med. 2019;200(11):1354-62.

24 Sterman DH, Mehta AC, Wood DE, Mathur PN, McKenna RJ Jr, Ost DE, et al. A multicenter pilot study of a bronchial valve for the treatment of severe emphysema. Respiration. 2010;79(3):222-33.

25 Fiorelli A, D’Andrilli A, Bezzi M, Ibrahim M, Anile M, Diso D, et al. Complications related to endoscopic lung volume reduction for emphysema with endobronchial valves: results of a multicenter study. J Thorac Dis. 2018; 10(Suppl 27):S3315-S25.

26 Gompelmann D, Lim HJ, Eberhardt R, Gerovasili V, Herth FJ, Heussel CP, et al. Predictors of pneumothorax following endoscopic valve therapy in patients with severe emphysema. Int J Chron Obstruct Pulmon Dis. 2016;11: 1767-73.

27 Gompelmann D, Herth FJ, Slebos DJ, Valipour A, Ernst A, Criner GJ, et al. Pneumothorax following endobronchial valve therapy and its impact on clinical outcomes in severe emphysema. Respiration. 2014;87(6):485-91.

28 Valipour A, Herth FJ, Burghuber OC, Criner G, Vergnon JM, Goldin J, et al. Target lobe volume reduction and COPD outcome measures after endobronchial valve therapy. Eur Respir J. 2014;43(2):387-96.
29 Gompelmann D, Benjamin N, Kontogianni $\mathrm{K}$, Herth F, Heussel CP, Hoffmann $\mathrm{H}$, et al. Clinical and radiological outcome following pneumothorax after endoscopic lung volume reduction with valves. Int J Chron Obstruct Pulmon Dis. 2016;11:3093-9.

30 Gompelmann D, Benjamin N, Bischoff E, Kontogianni K, Schuhmann M, Hoffmann $\mathrm{H}$, et al. Survival after endoscopic valve therapy in patients with severe emphysema. Respiration. 2019;97(2): 145-52.

31 van Geffen WH, Klooster K, Hartman JE, Ten Hacken NHT, Kerstjens HAM, Wolf RFE, et al. Pleural adhesion assessment as a predictor for pneumothorax after endobronchial valve treatment. Respiration. 2017;94(2):224-31.

32 Eberhardt R, Gompelmann D, Schuhmann M, Reinhardt H, Ernst A, Heussel CP, et al. Complete unilateral vs partial bilateral endoscopic lung volume reduction in patients with bilateral lung emphysema. Chest. 2012; 142(4):900-8.

33 Fishman A, Martinez F, Naunheim K, Piantadosi S, Wise R, Ries A, et al. A randomized trial comparing lung-volume-reduction surgery with medical therapy for severe emphysema. N Engl J Med. 2003;348(21):2059-73.

34 Darwiche K, Karpf-Wissel R, Eisenmann S, Aigner C, Welter S, Zarogoulidis P, et al. Bronchoscopic lung volume reduction with endobronchial valves in low-FEV1 patients. Respiration. 2016;92(6):414-9.

35 van Dijk M, Hartman JE, Klooster K, Ten Hacken NHT, Kerstjens HAM, Slebos DJ. Endobronchial valve treatment in emphysema patients with a very low DLCO. Respiration. 2020;99(2):163-70.

36 Klooster K, van Dijk M, Koster TD, Slebos DJ. First in human experience of the performance of the new 5.5-LP size zephyr endobronchial valve. Respiration. 2020;99(1):50-5.

37 Born T, Von Mallinckrodt C, Grandjean P-A, Tekeli N. Bronchoscopic lung volume reduction: do sequential endobronchial valve placements reduce pneumothorax rate? Eur Respir J. 2019;54(Suppl 63):PA3153.

38 Egenod T, Delacourt N, Simonneau Y, Vergnenegre A, Melloni B, Dusselier M. P573 - endobronchials valves: impact of the 2 step approach on pneumothorax rates. Am J Respir Crit Care Med. 2020;201:A6867.

39 Bellinger CR, Khan I, Chatterjee AB, Haponik EF. Bronchoscopy safety in patients with chronic obstructive lung disease. J Bronchol Interv Pulmonol. 2017;24(2):98-103.

40 Herzog D, Poellinger A, Doellinger F, Schuermann D, Temmesfeld-Wollbrueck B, Froeling V, et al. Modifying post-operative medical care after EBV implant may reduce pneumothorax incidence. PLoS One. 2015;10(5): e0128097.

41 Naunheim KS, Wood DE, Krasna MJ, DeCamp MM Jr, Ginsburg ME, McKenna RJ Jr, et al. Predictors of operative mortality and cardiopulmonary morbidity in the National Emphysema Treatment Trial. J Thorac Cardiovasc Surg. 2006;131(1):43-53. 